\title{
CHONDROMATOUS HAMARTOMA OF THE LUNG
}

\author{
BY \\ C. J. CARLSEN AND W. KIAER \\ From the Department of Thoracic Surgery and the University Institute of Pathological \\ Anatomy, University Hospital, Copenhagen
}

(RECEIVED FOR PUBLICATION JUNE 13, 1950)*

Chondromatous hamartoma of the lung is a pulmonary "tumour" which, as a result of the progress made in thoracic surgery during the last decade, is now being reported as not particularly uncommon. Since a lack of familiarity with this tumour may give rise to clinical as well as to pathological errors, it seems justified to describe it in some detail. At the same time we will report our experience based on nine cases.

The term hamartoma ( $\dot{\alpha} \mu \alpha \rho_{\rho} \dot{\alpha} \cup \varepsilon v=$ to fail or to err) was first used in 1904 by the German pathologist Albrecht, who defined it as a tumour-like malformation of an organ, made up of the normal elements of that organ, but with abnormal mixing and quantity of the components and perhaps an abnormal degree of differentiation. The hamartomata originally described by Albrecht were cavernomata of the liver, cavernomata of the spleen, and tuberous fibromata of the medullary substance of the kidney. Goldsworthy (1934) and Jaeger (1934) were the first to realize that the previously reported "chondromata " of the lung were not pure chondromata, but that they should be classified as hamartomas. The word "chondromatous" designated that cartilage was the dominant element.

The first reports of hamartomata of the lung were published in 1845 and 1847, when Lebert and Bleu described one typical case each. Both called them primary chondromata, but they realized that the growths did not look like typical chondromata. All the subsequently reported primary "chondromata" of the lung parenchyma-for which we have been able to procure the original reports with adequate histological descriptions-have proved to be hamartomata. Cornil and Ranvier (1884) denied the existence of ordinary chondromata in the lung parenchyma, but an exception is that reported by Edling (1938), who has kindly lent us his preparations. In this instance none of the sections showed changes suggesting chondromatous hamartoma with certainty, and the histological appearance does not differ from that of a chondroma. More than 100 hamartomata of the lung have been reported so far, and all show a typical histological picture with slight variations which correspond to the findings in our nine cases.

Hamartoma may occur anywhere in the lung; in the hilus (sometimes in relation to the large bronchi); in peripheral or subpleural situations, being sometimes attached to the pleura by a pedicle (Matras, 1929 ; Jaeger, 1934). They may in rare cases be encountered in the form of endobronchial polypi, but in this site they are not as common as true chondromata.

The size may vary within wide limits, from that of a hemp-seed (McDonald, Harrington, and Clagett, 1945) to a mass occupying the entire pleural cavity (Busse,

* Publication has been delayed because of our difficulty in importing radiographs from abroad.-ED. 
1907). The colour is white or whitish yellow, and in the subpleural type this colour may be seen shining through the pulmonary surface. As a rule they are globular or slightly oval, more rarely pear-shaped. The surface is evenly, finely nodular (Fig. 1).

At operation and on palpation, the growth is of the consistency of cartilage, firmly elastic and contrasting with the soft, uninvolved pulmonary tissue which surrounds them ; the tumour is without extensions or attachment to the surrounding tissues. When occurring in direct relation to a bronchus, they may be rather

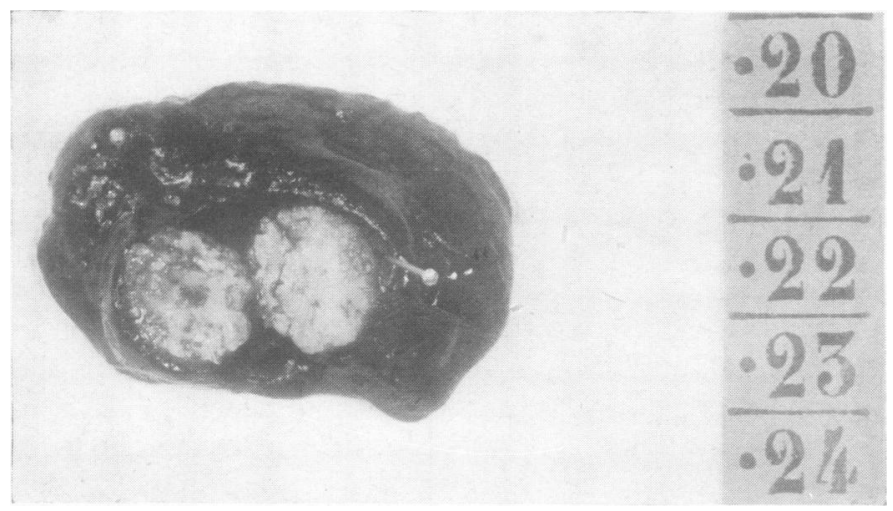

Fig. 1.-Chondromatous hamartoma of the lung in situ (Case 5). more fixed. The growth is surrounded by a fine capsule of loose connective tissue which cannot always be recognized macroscopically, and it is often so loose in the lung tissue that it cannot be photographed in situ, because it is apt to slip out after having been exposed by an incision. In only one of the reported cases (Courmont, 1895) a large branch of the pulmonary artery traversed the hamartoma, but this did not occur in the present series.

The endobronchial hamartoma is usually accessible by the bronchoscope and appears as a sessile, firm tumour with a smooth or finely nodular mucous surface, of a pinkish colour.

Histologically these hamartomata are characterized by cartilage disposed in lobules which are separated by loose, richly cellular, vascular connective tissue containing cavities lined with epithelium and some fatty tissue.

In the nine cases under discussion, the histological picture was uniform and characteristic, presenting nearly always the same elements in the same mutual relation. All nine cases had the following features in common: a richly cellular, coarsely lobulated cartilage tissue with the lobules separated by connective tissue of loose structure, forming a coarse or fine network. Cartilage was the dominant component, showing varying differentiation and irregular distribution of the cells ; the matrix is homogeneous, resembling hyaline. The loose connective tissue, which was seen beween the lobules and also in a narrow border on the finely nodular surface, had several common features, some of which contributed to differentiating hamartomata from true chondromata. This applied to peculiar clefts or cystic cavities, lined with small, dark, cuboid, uniform epithelial cells, interspersed with fat cells, strands and accumulations of lymphocytes, and cavernous, blood-filled vessels (Figs. 2 and 3 ).

In seven cases the connective-tissue cavities were lined with columnar as well as cubical epithelium. In three of these seven cases the epithelium was stratified and 
in one ciliated, corresponding exactly to respiratory epithelium. In three instances the cavities contained a fibrillar substance showing a positive mucin reaction. In addition to the large cavities there were, in several cases, small tubular gland structures lined with a single layer of dark, rather low columnar epithelium. The connective tissue also contained myxomatous areas and, in one case, small bundles of smooth muscle.

A large, central, connectivetissue matrix, like that found by Möller (1933) and to which

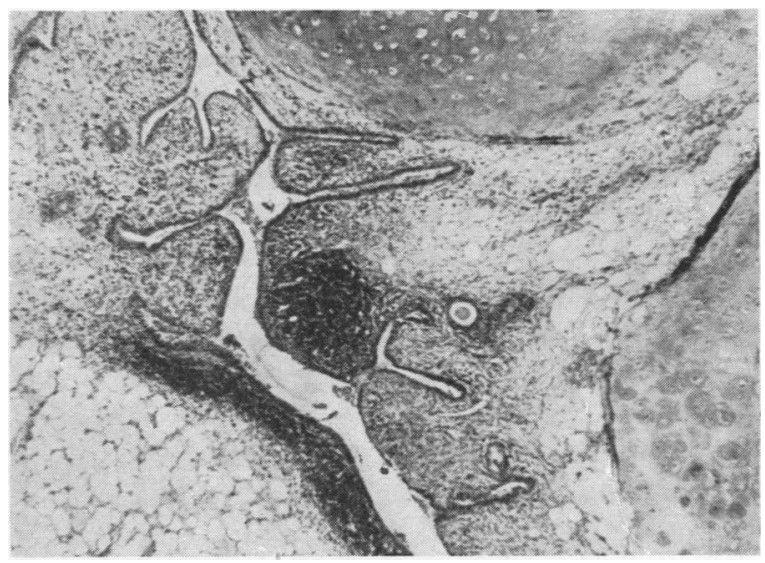

FIG. 2.-Photomicrograph (about $\times 40$ ) showing cartilage clefts lined with epithelium, fat cells, strands and accumulations of lymphocytes, and loose connective tissue (Case 6). she attached pathogenetic significance, was not demonstrated. Lymphocytes occurred in strands and small accumulations, but there was no truly lymphoid tissue like that found by Bayer (1930) in five cases, and by Goldsworthy (1934) in one. We encountered fibrillar areas in the cartilage ; in his six cases Will (1939) found a positive elastin reaction, and Jaeger (1934) mentions the occurrence of elastic fibres giving to the "tumour" a yellower colour.

In three cases there was some variation in the size of the cartilage cells and in one a certain polymorphism. In two the cartilage was, apart from being of irregular structure, disposed in short columns or in groups.

Before it was realized that the nine "tumours" made up a nosological entity, the possibility of histological malignancy was contemplated in a few cases, because

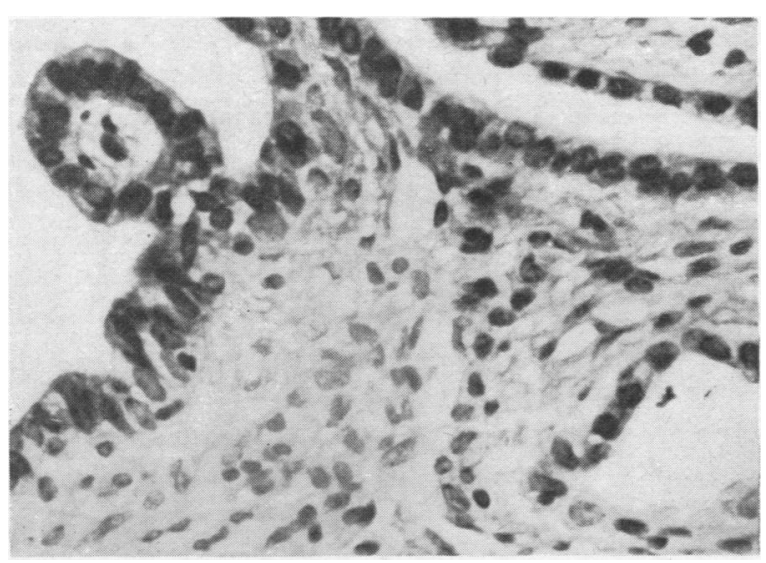

FIG. 3.-Photomicrograph (about $\times 500$ ) showing cleft lined with cubical and columnar epithelium (Case 6). of the varying shape or size of the cells and the considerably increased cellularity in places. A revision of all the cases, however, leaves a general impression that the tumours were innocent because the lobules were so sharply demarcated from each other and from the surrounding lung tissue, which failed to show any involvement. Thus all the growths have been interpreted as histologically benign; and this supposition was confirmed by the clinical course of the patients after operation. 
In eight cases, deposits of calcium were seen in the cartilage, and calcification was marked in two. Ossification or deposition of pigment was not seen. The surrounding lung tissue was normal in all instances, apart from slight compression atelectasis in the immediate surroundings of the "tumour." A comparison of the histological preparations from our nine cases shows a certain relationship between the degree of calcification and the occurrence of myxomatous connective tissue on the one hand and the condition of the epithelium on the other hand; the more pronounced the calcification and/or the myxomatous degeneration of the connective tissue, the more common the occurrence of small-celled, dark, simple cubical epithelial lining without cilia in the clefts. Probably this is a sign of arrested growth, accompanied by or produced by the degenerative changes.

The material does not afford contributions to the histogenesis. This aspect of the matter has been discussed in detail by Möller, who is of the opinion that the eause of the tumours is a localized abnormality occurring in the development of the bronchi. She suggests that, instead of the normal foetal eversion of the terminal tubes of the bronchial tree, there may be in one site inversion of epithelium and mesenchyma analogous with the growth of intracanalicular mammary fibroadenoma. This affords an explanation partly of the structure of hamartoma and partly of the occurrence in the tumour of all the normal bronchial elements. Feller (1922), Hickey and Simpson (1926), and Jaeger found that the coarse structure of the tumour might also resemble intracanalicular mammary fibro-adenoma. Hickey and Simpson claim that the lesion is congenital, arguing that anthracotic pigment has never been encountered in a hamartoma, even in severely anthracotic lungs: but this is hardly decisive, since the hamartoma may lack functional connexions with the lung, as was emphasized by Goldsworthy (Table I). We share the view that hamartoma of the lung is probably a congenital malformation, and thus were surprised not to find any report of the condition in children. In the course of our studies on the subject, however, a most interesting case of chondromatous hamartoma of the lung in a newborn infant was reported by Jones (1949).

The risk of malignancy occurring in a hamartoma of the lung is presumed to be minimal, and the literature does not contain any case of malignant, metastasizing, hamartoma of the lung.

Greenspan (1933) has described a primary osteoid chondrosarcoma of the lung which exhibited local invasion, and it could not be excluded that this was a case of a pulmonary hamartoma undergoing malignant degeneration, but epithelial structures were not demonstrated. Tapie (1892) reported an osteoma which he found in immediate contact with a malignant epithelial tumour situated in the peripheral area of the lung of a 28-year-old patient. In addition, both lungs were strewn with epithelial neoplastic infiltrations. It appears to us to be very doubtful that this was a hamartoma undergoing malignant degeneration, but we were unable to see the original report. Lowell and Tuhy (1949) described a chondrosarcoma filling both pulmonary arteries and spreading into the lung tissue. The authors discussed the possibility of a malignant hamartoma, but they considered it unlikely in view of the architecture and site of the tumour. Simon and Ballon (1947) have reported a histologically verified hamartoma situated centrally in the lung and showing considerable cellular variations and invasion into the mediastinal fatty tissue in one site. No metastases were demonstrated. Although we consider it unlikely that 


\begin{tabular}{|c|c|c|c|c|c|c|c|c|c|c|c|c|c|c|c|c|c|c|}
\hline$a$ & 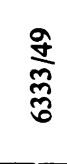 & + & $1+$ & $1+$ & + & 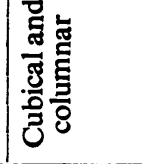 & + & + & + & $1+$ & $*$ & $*$ & 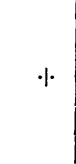 & 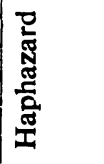 & $\%$ & + & 0 & $\psi$ \\
\hline$\infty$ & 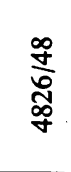 & + & + & + & + & 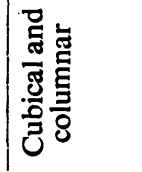 & + & + & $1+$ & $1+$ & 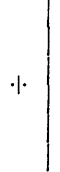 & $*$ & + & 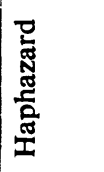 & $\psi$ & + & సి & $\psi$ \\
\hline$r$ & $\frac{\frac{g}{a}}{\frac{d}{m}}$ & + & + & + & + & ठृ. & + & + & + & + & + & $\psi$ & $*$ & 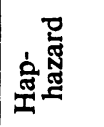 & $\psi$ & + & ¿ & $\psi$ \\
\hline 0 & 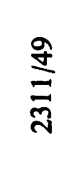 & + & + & $1+$ & + & 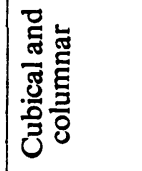 & $1+$ & + & + & $1+$ & $\psi$ & $\psi$ & $*$ & 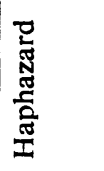 & $\psi$ & + & 8 & $\psi$ \\
\hline$n$ & 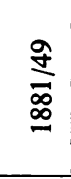 & + & + & +1 & + & 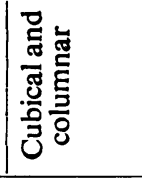 & + & + & +1 & + & $\psi$ & $\psi$ & + & 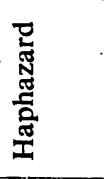 & 忄 & + & $\cong$ & $\%$ \\
\hline$\forall$ & 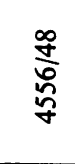 & + & $1+$ & $1+$ & + & 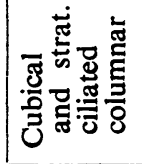 & $*$ & + & + & + & $\psi$ & $*$ & $\psi$ & 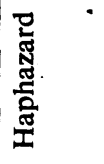 & 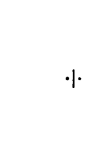 & + & 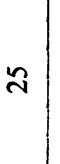 & 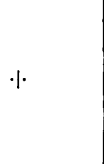 \\
\hline$m$ & $\underset{\substack{\tilde{N} \\
\tilde{n}}}{n}$ & + & $1+$ & $1+$ & + & 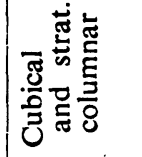 & $1+$ & + & + & + & $\psi$ & + & $*$ & 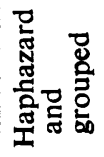 & $\psi$ & + & $?$ & . \\
\hline$N$ & 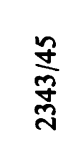 & + & $1+$ & $1+$ & + & 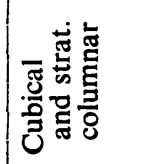 & $1+$ & + & + & + & 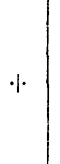 & $\psi$ & $*$ & 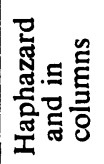 & $\psi$ & + & $a$ & 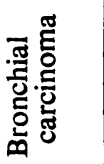 \\
\hline- & 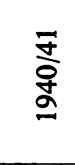 & + & $1+$ & $1+$ & + & 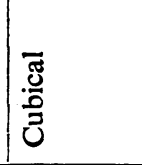 & $1+$ & + & $1+$ & $1+$ & $\psi$ & $\psi$ & + & 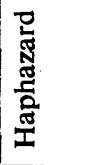 & $\psi$ & + & $\approx$ & 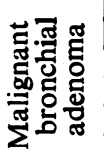 \\
\hline $\begin{array}{l}\dot{z} \\
\dot{y} \\
\dot{z}\end{array}$ & 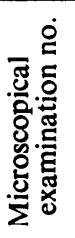 & 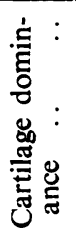 & 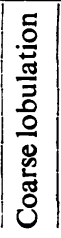 & $\mid$\begin{tabular}{c|}
$:$ \\
\\
$\frac{0}{\overline{8}}$ \\
$\frac{\pi}{\tilde{E}}$ \\
$\dot{\pi}$
\end{tabular} & 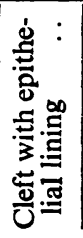 & 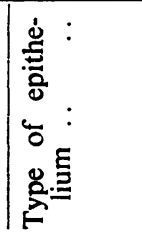 & 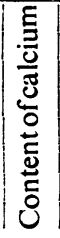 & 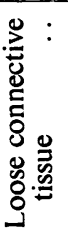 & 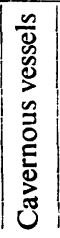 & 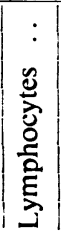 & 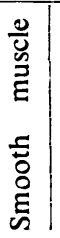 & 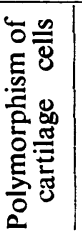 & 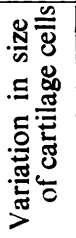 & 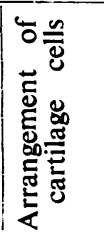 & 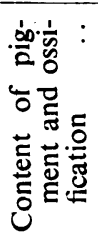 & 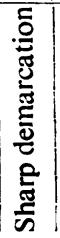 & 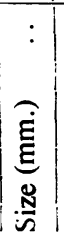 & $\begin{array}{l}\text { 嘿号 } \\
\text { 总 } \\
\text { 总至 }\end{array}$ \\
\hline
\end{tabular}


hamartoma of the lung would ever undergo malignant degeneration, it must be emphasized that theoretically the possibility cannot be excluded, since other congenital tumour-like malformations may undergo such degeneration. Among the "malignant" or suspected cases reported in the literature, that of Simon and Ballon appears to be the most probable, and the authors venture to suggest that the tumour "showed features which upon objective grounds do not permit one to exclude the possibility of malignancy." Two of our "tumours" coexisted with primary malignancy of the lung. In one of them (previously included in a series of bronchial adenomata reported by Engelbreth-Holm, 1944) a malignant adenoma was found in the left main bronchus, and in the left upper lobe a hamartoma, $2 \frac{1}{2} \mathrm{~cm}$. in diameter, unconnected with the malignant adenoma. In the other case, an endobronchial, left-sided hamartoma, almost $1 \mathrm{~cm}$. in diameter, was found in a patient with a right-sided bronchogenic carcinoma. Cid (1940) reported a case of bronchogenic carcinoma coexisting with a small subpleural hamartoma. No mention was made of primary malignancy of the lung in the remaining more than 100 reported cases. There was no evidence of genetic relationship, and presumably these two cases may be interpreted as coincidence.

Formerly, hamartoma of the lung was regarded as a pathological curiosity of no clinical interest, but the progress of thoracic surgery has disturbed its seclusion. Owing to the ever-increasing application of chest radiography (in case-finding surveys and other routine studies) it must often be decided which procedure to follow in a case of a round, sharply demarcated, solid pulmonary infiltration detected by chance.

The present series comprises three necropsied and six operated cases. The former were found by perusal of the necropsy records for the last eight years. We looked for "chondroma of the lung" within which group all the cases were found. The first (Case 8) was detected accidentally in a man aged 64, who died from suicidal barbiturate poisoning; the second (Case 1) occurred in another man, aged 72, who died from malignant bronchial adenoma; the third (Case 9) was in a man, aged 69, who died from Addison's disease with tuberculosis of the adrenal glands.

Among the six operated cases, an endobronchial hamartoma localized in the left main bronchus was an accidental bronchoscopic finding in a man, aged 59 (Case 2), who was bronchoscoped because of symptoms of a subsequently verified right-sided bronchial carcinoma. All the remaining five were chance findings in the course of mass radiography or other routine radiological investigations of the lungs. None of the five patients exhibited subjective or objective signs of pulmonary disease except a round, sharply demarcated, solid shadow in the lung field. An exact diagnosis could not be made in any by means of the ordinary diagnostic procedures of Wassermann reaction, Mantoux test, smears and culture to detect tuberculosis, examination of the sputum for neoplastic cells, bronchoscopy, tomography, and bronchography. These five cases occurred among 33 patients referred to the Department and operated upon because the pulmonary shadows and the ages of the patients gave rise to a suspicion of pulmonary malignancy.

A diagnosis of hamartoma of the lung cannot be made before operation and microscopical examination. Earlier authors have set up certain radiography criteria which suggest the diagniosis of hamartoma, but among the present series of 33 . 


\begin{tabular}{|c|c|c|c|c|c|c|c|c|c|c|c|c|c|}
\hline$a$ & 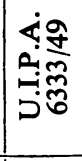 & rog & + & $\%$ & 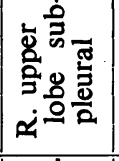 & $\%$ & 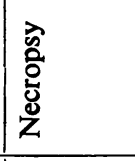 & $*$ & . & 1 & 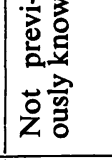 & 1 & 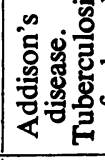 \\
\hline$\infty$ & & rot & + & $*$ & 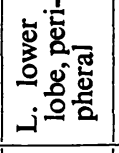 & r & 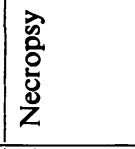 & $\%$ & . & 1 & 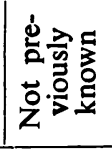 & 1 & 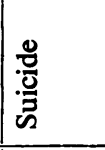 \\
\hline r & 雨 & roo & $*$ & + & 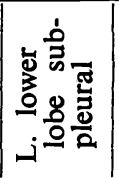 & 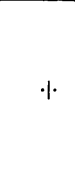 & 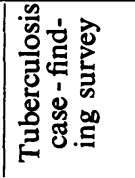 & a. & 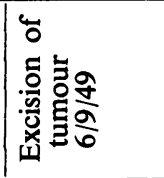 & 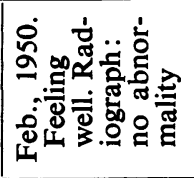 & 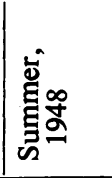 & $\stackrel{\circ}{z}$ & 1 \\
\hline 0 & 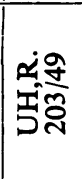 & rog & $\psi$ & + & 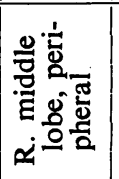 & * & 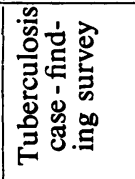 & a. & 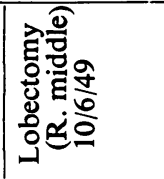 & 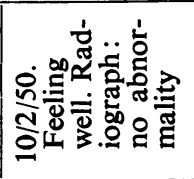 & 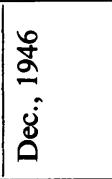 & 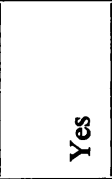 & 1 \\
\hline$n$ & 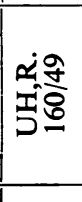 & roo & $\psi$ & + & 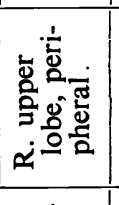 & 忄 & 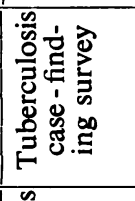 & o. & 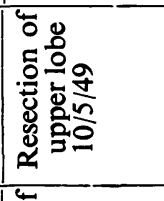 & 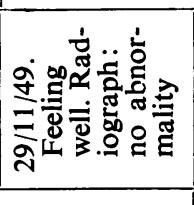 & 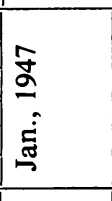 & $\underset{\nu}{y}$ & 1 \\
\hline+ & 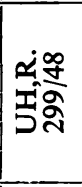 & $a+\tilde{G}$ & $*$ & + & 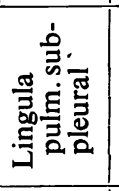 & $*$ & 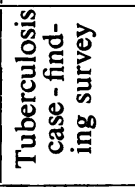 & 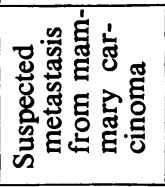 & 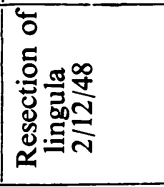 & 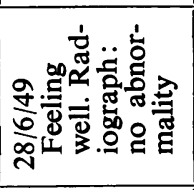 & 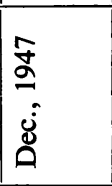 & . & 1 \\
\hline$m$ & 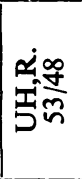 & $0+n$ & $\%$ & + & 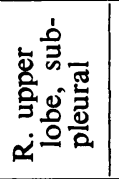 & 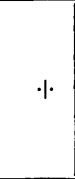 & 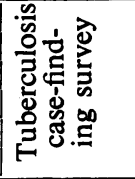 & a. & 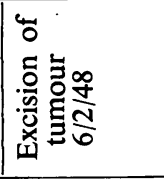 & 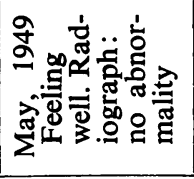 & $\frac{\frac{a}{2}}{\frac{2}{2}}$ & $\stackrel{\circ}{z}$ & 1 \\
\hline$N$ & 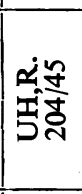 & roô & Ð & + & 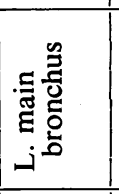 & + & 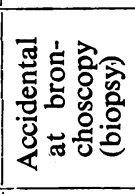 & 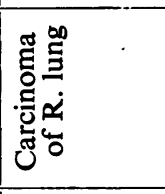 & 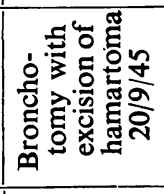 & 1 & 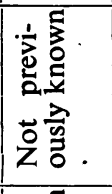 & 1 & 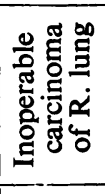 \\
\hline- & 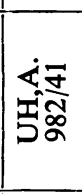 & ron & + & 1 & 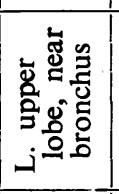 & + & 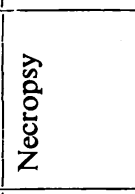 & 1 & 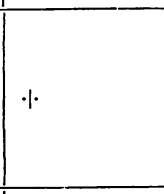 & 1 & 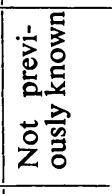 & 1 & 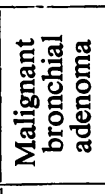 \\
\hline $\begin{array}{l}\dot{0} \\
z \\
\mathbb{\Xi} \\
\tilde{J}\end{array}$ & & 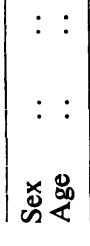 & 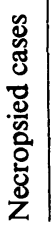 & 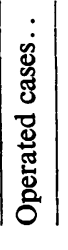 & $\begin{array}{l}: \\
: \\
\stackrel{8}{2}\end{array}$ & 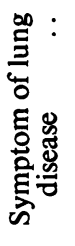 & $\mid \begin{array}{c}: \\
\frac{5}{.00} \\
\frac{.00}{0} \\
0\end{array}$ & 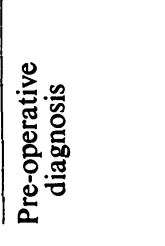 & 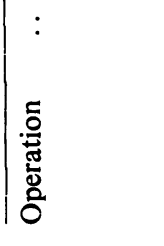 & 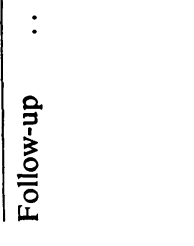 & 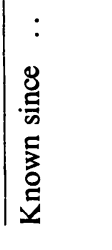 & 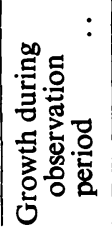 & 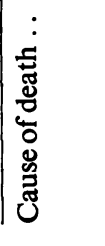 \\
\hline
\end{tabular}




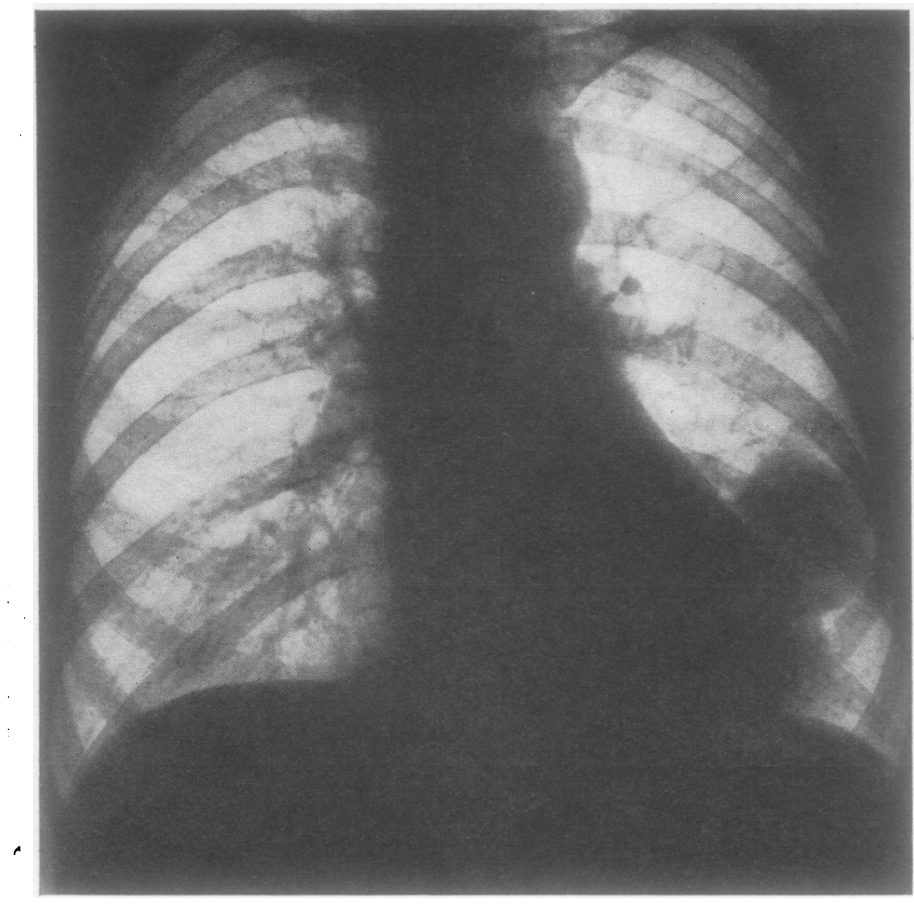

Fig. 4

FIGs. 4 and 5.-Typical radiographic appearance of hamartomata.

FIG. 5

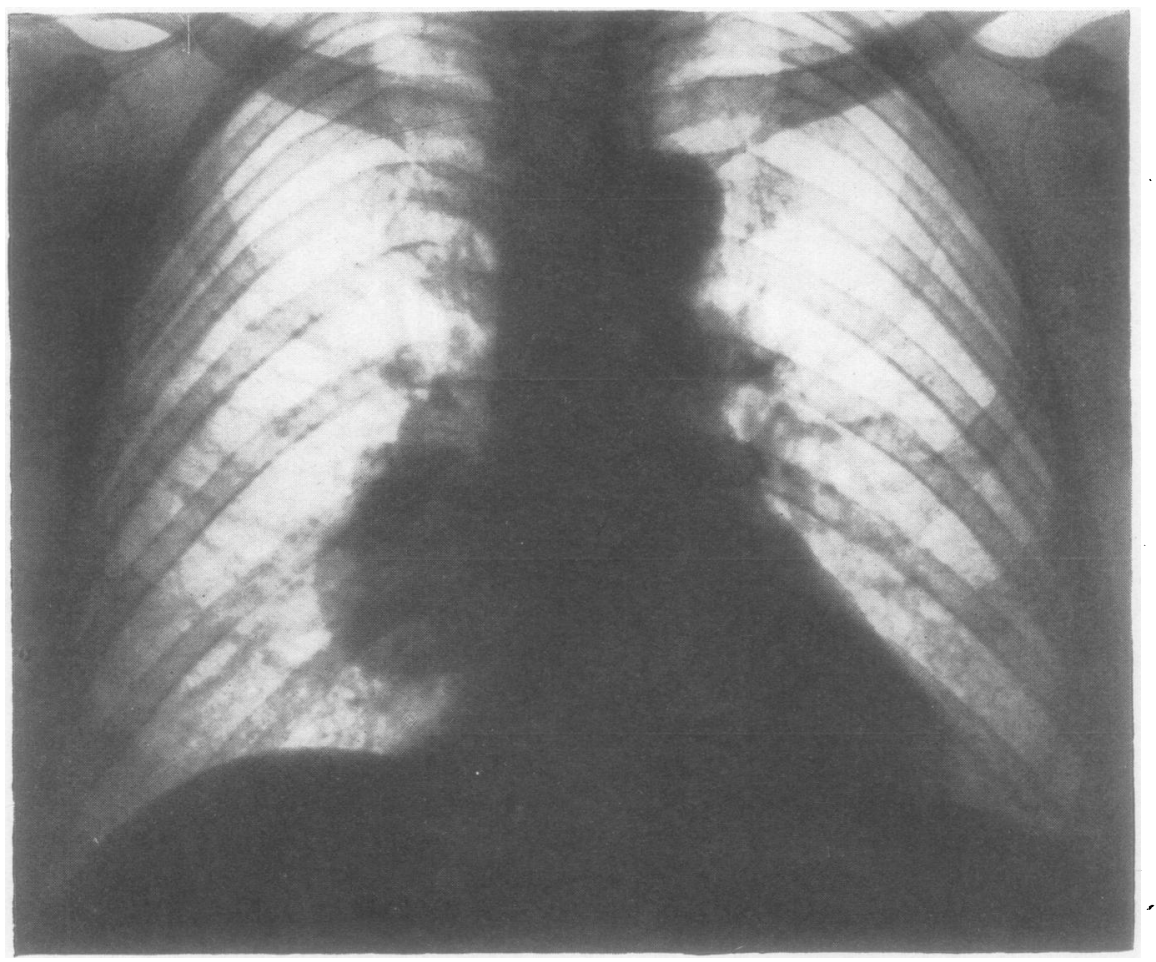

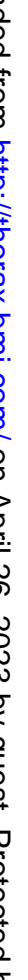


four patients, who proved to be suffering from malignancy, exhibited exactly the same appearances as the patients with hamartoma.

Despite Benninghoven and Peirce's (1933) statement that “. . . the neoplasm is sufficiently characteristic roentgenographically to permit identification without microscopic study," the writers warn against the belief that a clinical or radiological diagnosis can be made with any degree of certainty. Dealing with the radiological diagnosis of hamartoma, Hall arrived at the conclusion that the tendency of the "tumour" to calcify or ossify is of the utmost diagnostic significance. If large hamartomata contain calcium or bone-like structures, a radiological diagnosis may be made with a certain measure of accuracy, but small shadows, which are most common, "are more likely to simulate metastatic nodules or primary bronchogenic carcinomas" and cannot be diagnosed in this way. The cystic cavities in hamartomata may be large ; in McGlumphy's (1924) fourth case, for example, it measured $9 \mathrm{~mm}$. On the films, such cavities appear in the form of translucent areas in the shadow (tomography), and such translucency does not decisively militate against a diagnosis of chondromatous hamartoma. In our opinion, patients exhibiting this clinical picture should be operated upon without delay, unless there are serious contraindications to surgery.

If the operator is familiar with the picture the operation often, but not always, affords a hint indicating the possibility of hamartoma. The typical findings are a normal pleura, a globular, sharply demarcated nodule, hard as cartilage, situated in normal lung tissue and without hilar or pleural changes ; the nodule may upon occasion shine through the pleura. The tumour is easy to remove and may even slip out of its site as a result of the pressure necessary to hold the lung. This happened in one of our cases, and Legg reported a similar experience in the course of a necropsy as early as 1875 . If the procedure is segmental resection of the lung, lobectomy, or pneumonectomy, the same hazard applies when the preparation is to be examined after the operation.

In certain cases it is no doubt useful to examine frozen sections of the tumour as recommended by McDonald and others (1945). This will probably confirm the diagnosis, since the histological appearance is unmistakable in typical cases. We have not used this method yet, and some difficulty will arise in cutting frozen sections of tumours with marked calcification. As emphasized by McDonald and others an exact diagnosis in the course of the operation is a great help in preserving as much healthy lung tissue as possible.

Treatment should, in our opinion, consist in removal of the hamartoma, primarily because it cannot be differentiated from a malignant neoplasm. Moreover, endobronchial hamartoma must be removed because of the risk of complications in the form of bronchial obstruction as in Ulrich's (1941) and Paul's (1930) cases. It is known from the literature and from the present series that hamartomas may grow. Those localized in the lung tissue may give rise to secondary pulmonary changes causing symptoms, but practically all the reported cases have failed to cause subjective symptoms. If an exact diagnosis could be made without operation, it would be permissible to observe a patient with non-endobronchial hamartoma, and surgical treatment would probably seldom be required. In the future there will be a tendency to decide on observation of children and adults under 35 years of age who exhibit a round, sharply demarcated shadow in the lung field and no 
symptoms, but the period of observation must be painstaking. We are not prepared to express any final views on this matter until our series of now more than 33 operated cases has been thoroughly analysed.

\section{SUMmary}

Nine cases of chondromatous hamartoma of the lung are presented. Six were operation findings and three accidental post-mortem findings. On the basis of the literature and our own series, the clinical, radiological, and pathological diagnosis is discussed, as well as the prognosis and treatment.

\section{REFERENCES}

Albrecht, E. (1904). Verh. dtsch. path. Ges., 7, 153.

Bayer, R. (1930). Virchows Arch., 274, 350.

Benninghoven, C. D., and Peirce, C. B. (1933). Amer. J. Roentgenol., 29, 805.

Bleu (1847). Bull. Soc. Anat. Paris, 22, 408. Cited by Jaeger.

Borelius, J., and Sjövall, E. (1915). Nord. med. Ark., 48, I, No. 12, 1.

Busse, O. (1907). Virchows Arch., 189, 1.

Cid, J. M. (1940). Arch. Soc. argent. Anat. norm. patol., 2, 199. Cited by Jones.

Cornil, A. V., and Ranvier, L. A. (1884). Manuel d'histologie pathologique, 2nd ed., vol. 2, p. 140. Paris.

Courmont, P. (1895). Mem. Soc. Sci. méd. Lyon, 35 (Part 2), 13. Cited by Hickey and Simpson. Edling, N. P. (1938). Acta radiol., Stockh., 19, 44.

Engelbreth-Holm, J. (1944-5). Acta chir. scand., 90, 383.

Feller, A. (1922). Virchows Arch., 236, 470.

Goldsworthy, N. E. (1934). J. Path. Bact., 39, 291.

Greenspan, E. B. (1933). Amer. J. Cancer, 18, 603.

Hall, W. C. (1948). Amer. J. Roentgenol., 60, 605.

Hickey, P. M., and Simpson, W. M. (1926). Acta radiol., Stockh., 5, 475.

Husfeldt, E., and Carlsen, C. J. (1950). Thorax, 5, 229.

Jaeger, L. (1934). Contribution a l'étude des hamartomes pulmonaires, Thèse de Paris.

Jones, C. J. (1949). Arch. Path.,48, 150.

Lebert, H. (1845). Physiologie pathologique, vol. 2, p. 213. Paris.

Legg, J. (1875). Trans. path. Soc., Lond., 26, 11.

Lowell, L. M., and Tuhy, J. E. (1949). J. thorac. Surg., 18, 476.

Matras, A. (1929). Klin. Wschr., 42, 1369.

McDonald, J. R., Harrington, S. W.. and Clagett, O. T. (1945). J. thorac. Surg., $14,128$.

McGlumphy, C. B. (1924). J. Cancer Res., 8, 482.

Möller, A. (1933). Virchows Arch., 291, 478.

Paul, F. (1930). Mschr. Ohrenheilk., 64, 669.

Simon, M. A., and Ballon, H. C. (1947). J. thorac. Surg., 16, 379.

Tapie (1892). Midi méd., Toulouse, 1, 385. Cited by Hickey and Simpson.

Ulrich, K. (1941). Arch. Ohr.-, Nas.- u. KehlkHeilk., 149, 478.

Will, G. (1939). Schweiz. Z. Path. Bact., 2, 193. 